\title{
Predicting weight-loss using differential equations (PRELUDE)
}

\author{
A. $\operatorname{Egan}^{1}$, J. Rayman ${ }^{1}$, M. P. Rayman ${ }^{1}$ and A. Collins ${ }^{1}$ \\ ${ }^{1}$ Faculty of Health \& Medical Sciences, University of Surrey, Guildford, Surrey, GU2 $7 X H$
}

$26 \%$ of English adults are classified as obese and a further $35 \%$ are overweight ${ }^{(1)}$, reflecting the fact that the UK has the $6^{\text {th }}$ highest rate of obesity globally ${ }^{(1)}$. Levels of obesity are rising alarmingly despite $75 \%$ of adults reportedly attempting to lose weight ${ }^{(1)}$. The ' 3500 $\mathrm{kcal}$ rule' or $500 \mathrm{kcal} /$ day restriction, is used frequently in clinical practice and should result in a weight-loss of 1 pound/week ${ }^{(2)}$ though is consistently shown to overestimate weight-loss ${ }^{(2)}$. This can be explained by physiological adaptations - adaptive thermogenesis designed to protect our body's energy stores ${ }^{(4)}$ that manifest as a depression in resting metabolic rate ${ }^{(3)}$. These dynamic changes are unaccounted for in current weight-loss strategies. We therefore aimed to propose an alternative mathematical approach to weight-loss that accounts for the contribution of adaptive thermogenesis, as well as diet- induced thermogenesis and body-composition.

The initial model used baseline values of weight, energy intake and energy expenditure. Values for resting metabolic rate were estimated using predictor equations ${ }^{(4)}$ and values for body-composition were obtained from relevant studies ${ }^{(5,6)}$. A basic model was defined and produced as an ordinal differential equation illustrating a static model of weight-loss. The model was refined through addition of an accurate formulation of adaptive thermogenesis. The new function was solved numerically with appropriate parameters. The final model included an accurate formulation of fat-free mass. The model was validated by comparison to three independent weight-loss studies varying the degree of caloric restriction ${ }^{(7)}$, macronutrient content ${ }^{(8)}$ and physical-activity level ${ }^{(9)}$.

The most accurate results were observed in the study varying physical-activity level, where our model predicted weight-loss to $100 \%$ accuracy in both the caloric-restriction and the caloric-restriction-plus exercise groups. A high degree of accuracy was also observed in the study varying degree of caloric restriction, with predicted weight-loss deviating only by 1 and $2 \mathrm{~kg}$ from observed weight-loss in the low-calorie-diet and very-low-calorie-diet groups, respectively. The largest margin of error was observed in the macronutrientmanipulation study, with differences of 5-7 kg observed between predicted and actual weight-loss in the high-fat and highcarbohydrate groups, respectively (Table 1).

\begin{tabular}{|c|c|c|c|c|c|}
\hline \multirow[b]{2}{*}{ Study \# } & \multirow[b]{2}{*}{ Dietary Intervention } & \multicolumn{2}{|c|}{ Study Data } & \multicolumn{2}{|c|}{ Model 3} \\
\hline & & Actual end weight $(\mathrm{kg})$ & Actual weight-loss (kg) & Predicted end weight $(\mathrm{kg})$ & Predicted loss $(\mathrm{kg})$ \\
\hline 1 & LFHC $^{1}$ & 99 & 12 & 106.37 & 5 \\
\hline 2 & $\mathrm{HFLC}^{2}$ & 101 & 11 & 106.33 & 6 \\
\hline 3 & $\mathrm{CR}^{3}$ & 73 & 8 & 72.63 & 8 \\
\hline 4 & $\mathrm{CR} \& \mathrm{EX}^{4}$ & 75 & 8 & 74.84 & 8 \\
\hline 5 & $\mathrm{LCD}^{5}$ & 84 & 8 & 83.08 & 9 \\
\hline 6 & VLCD $^{6}$ & 83 & 9 & 84.86 & 7 \\
\hline
\end{tabular}

${ }^{1}$ Low-fat high-carbohydrate

${ }^{2}$ High-fat low-carbohydrate

${ }^{3}$ Caloric restriction

${ }^{4}$ Energy expended by exercise

${ }^{5}$ Low-calorie diet

${ }^{6}$ Very low-calorie diet

Our model provides further evidence challenging the $3500 \mathrm{kcal}$ rule by illustrating the physiological influence of adaptive thermogenesis, diet-induced thermogenesis and body-composition on weight-loss. It predicts weight-loss achieved through caloric restriction and exercise to a high level of accuracy, however further refinement is needed to account for the impact of macronutrient composition on weight-loss. Minimal input is required to generate accurate results making our model highly applicable in a clinical environment.

1. Baker, C. (2018). House of Commons Library

2. Thomas DM, et al. (2014). J Acad Nutr Diet 114(6), 857-861.

3. Redman LM, Ravussin E (2011). Antiox Redox Signal 14(2), 275-287.

4. Miller S et al. (2013). Topics Clin Nutr 28(2), 120-135.

5. Gallagher D, Delegge M (2011). J Parenteral Enteral Nutr 35(5_suppl).

6. Ghoch ME (2013). Http://isrctn.org/

7. Vink RG, et al. (2016). Obesity, 24(2), 321-327.

8. Veum VL, et al. (2016). AJCN, 105(1), 85-99.

9. Redman LM, et al. (2007). J Clin Endocrinol Metab 92(3), 865-872. 